\title{
Significance of fibre length in the clearance of asbestos fibres from the lung
}

\author{
A. MORGAN, R. J. TAlBOT, AND A. HOLMES \\ From the Environmental and Medical Sciences Division, Atomic Energy Research Establishment, Harwell, \\ Oxfordshire OX11 ORA
}

ABSTRACT Rats were exposed by inhalation to radioactive anthophyllite asbestos. Animals were then killed serially over a period of 205 days and the fibre content of the lungs measured radiometrically. The lungs were subjected to selective bronchopulmonary lavage and the mean fibre content determined of free cells recovered from the alveolar spaces. The length distributions of fibres recovered from the lungs by lavage, and of those remaining in the lungs following lavage, were measured. Short (less than $5 \mu \mathrm{m}$ ) fibres are cleared from the lung via the conducting airways more efficiently than longer fibres and fibres exceeding $50 \mu \mathrm{m}$ in length are not removed from the lungs by this route. Although fibres of about $200 \mu \mathrm{m}$ in length were present in all the lungs examined, the longest which could be recovered by lavage, once fibre deposited in the airways had been cleared, was only about $100 \mu \mathrm{m}$ decreasing to $60-70 \mu \mathrm{m}$ after 205 days. It is suggested that long fibres are more liable than short to penetrate the alveolar wall as they tend to bridge the alveolar ducts and alveoli.

It has been shown by Morgan et al. (1977a) using autoradiographic techniques that when small amounts of asbestos are deposited in the rat lung the fibres tend, in the course of time, to accumulate not only in the tracheobronchial lymph nodes but also in subpleural foci. Similar peripheral accumulations of dust have been observed in the rodent lung following exposure to beryllium oxide (Sanders and Cannon, 1975) and in rodent, dog and human lungs following exposure to plutonium oxide (Clarke and Bair, 1964; Sanders and Dagle, 1974; Voelz et al., 1976). If asbestos fibres are transported in a similar manner to the periphery of the human lung, this could be an important factor in the aetiology both of asbestosis, which generally appears to affect subpleural areas first (Becklake, 1976) and of asbestos-induced mesothelial tumours. If, as seems likely, this movement occurs within or through the alveolar wall rather than over its surface, then it is important to know how the dimensions of asbestos fibres affect their penetration into the interstitium.

To investigate the fate of asbestos fibres deposited in the rat lung, the selective bronchopulmonary lavage procedure of Brain and Frank (1973) has been

Received for publication 16 August 1977

Accepted for publication 29 November 1977 applied by Morgan et al. (1977b) to the lungs of animals killed serially following exposure to radioactive asbestos by inhalation. In this technique the initial washings are with a balanced salt solution containing calcium and magnesium. Under these circumstances relatively few cells (only those which are loosely attached) are washed out of the lung. These include alveolar macrophages which are present on the mucous layer in the conducting airways and which are in the process of being removed from the lung. On subsequent washing with physiological saline, in the absence of divalent cations, alveolar macrophages detach themselves from the alveolar wall and are recovered in large numbers. To determine the length distribution of fibres present in the various washes, a wet digestion technique has been developed which enables certain types of fibre to be recovered, not only from washings but also from lung tissue, for examination by either optical or electron microscopy. The advantage of a wet oxidation procedure is that the shrinkage of lung tissue and consequent fragmentation of fibres (Ashcroft and Heppleston, 1973) which may occur during drying and ashing is avoided.

In the experiment described below, rats were exposed to radioactive anthophyllite asbestos and killed serially over a period of 205 days. In addition 146 
to measuring the amount of fibre retained in the lung and in the alveolar macrophages, the length distributions of fibres recovered in the various washes and in the lavaged lungs were measured.

\section{Methods}

MATERIAL

The standard reference sample of anthophyllite (Timbrell et al., 1968) prepared under the auspices of the Union Internationale Contre le Cancer (UICC) was used. The fibres of this material are relatively thick (Timbrell et al., 1970a) and can be resolved under the optical microscope with phase contrast. Before use the material was made radioactive by irradiation in a thermal neutron flux of $6 \times 10^{12}$ neutrons $\mathrm{cm}^{-2} \mathrm{sec}^{-1}$ for 14 days.

\section{EXPOSURE}

Fourteen male Albino rats, about five months old, were exposed to a concentration of airborne fibre of $35 \mathrm{mg} \mathrm{m}^{-3}$ for a total of 8.4 hours on three consecutive days. At the end of the third and final exposure the animals' lungs contained about $190 \mu \mathrm{g}$ of anthophyllite, mainly in the alveolar region but with a small amount in the conducting airways. Animals were killed serially, the first immediately after the final exposure and the last seven months later.

\section{LAVAGE PROCEDURE}

This has been described by Morgan et al. (1977b). Each lung was lavaged four times with balanced salt solution (Tyrodes) and ten times with physiological saline. The lungs were massaged while being washed with the latter. Consecutive washes were combined in pairs. Typically, about $8 \times 10^{6}$ cells were recovered which, in the strain of Wistar rats used, represent about half the total number of free cells present in the alveolar spaces. It is considered that more than $95 \%$ of the free cells recovered in this way were alveolar macrophages. Polymorphonuclear leucocytes were occasionally identified. Radiometric measurements enabled the amount of fibre recovered in each wash to be determined and the total number of cells present were estimated using a FuchsRosenthal haemocytometer. Most of the fibres which had not been phagocytosed were removed from the lung by the balanced salt solution washes so that measurements on the subsequent physiological saline washes enabled the mean fibre content of the macrophages from the alveolar spaces to be determined.

RECOVERY OF FIBRES FOR MICROSCOPIC EXAMINATION

Selected lung washes were centrifuged in glass tubes. The supernatant was discarded and $10 \mathrm{~cm}^{3}$ of $\mathrm{N}$
$\mathrm{KOH}$ added followed by $0.5 \mathrm{~cm}^{3}$ of $100 \mathrm{vol} \mathrm{H}_{2} \mathrm{O}_{2}$. The reaction was allowed to proceed at room temperature and, when the vigorous reaction had subsided, the tubes were heated on a boiling water bath. Finally a further $0.5 \mathrm{~cm}^{3}$ of $\mathrm{H}_{2} \mathrm{O}_{2}$ was added and heating continued until there was no effervescence. The resulting suspensions were acidified and diluted to $25 \mathrm{~cm}^{3}$ in standard volumetric flasks. Aliquots were filtered on Millipore GS membrane filters $(2.5 \mathrm{~cm} d)$ to give fibre densities of about $1 \mu \mathrm{g}$ $\mathrm{cm}^{-2}$. After drying, a $90^{\circ}$ sector was cut from the filter, transferred to a microscope slide and cleared with acetone vapour. Samples were mounted in neutral mounting medium.

Because rat lungs contain silicon it is necessary to modify the above procedure when analysing lung tissue, to prevent the precipitation of silica. In the experiments described here the diaphragmatic lobe of the right lung was digested by treatment with $\mathrm{H}_{2} \mathrm{O}_{2}$ in $\mathrm{N} \mathrm{KOH}$. As significant losses may occur when free fibres are centrifuged, yttrium (1 mg) was added and the resulting gelatinous precipitate of $\mathrm{Y}(\mathrm{OH})_{3}$ centrifuged to scavenge the fibres present in suspension. The supernatant containing most of the silicon was discarded while the precipitate was dissolved in dilute acid and made up to $25 \mathrm{~cm}^{3}$. Appropriate aliquots were filtered as described above. Radiometric methods were used to check the overall recovery of fibre which exceeded $90 \%$ in all cases. All reagents were filtered through a membrane filter before use.

FIBRE LENGTH DISTRIBUTION

Fibres were measured under phase contrast with a Zeiss Universal binocular microscope using a magnification of $\times 512$ (eyepiece $\times 8$, Optovar $\times$ $1 \cdot 6$, objective $\times 40$ ) and Porton-type eyepiece graticule. Fibres were classified into the following lengths: less than 5, 5-9.9, 10-19.9, 20-40 and longer than $40 \mu \mathrm{m}$. The usual convention was adopted that particles were classified as fibres only if their aspect ratio exceeded 3 . Normally at least 200 fibres were measured. However, because most of the fibres deposited were less than $10 \mu \mathrm{m}$ in length, the distribution of fibres over $10 \mu \mathrm{m}$ long was more accurately assessed by measuring 100 such fibres and correcting the initial distribution accordingly.

\section{Results}

RETENTION OF ANTHOPHYLLITE IN THE LUNGS

The retention of anthophyllite in the lungs of rats killed at various times after exposure is shown in Fig. 1. Immediately after the final exposure the average level was about $190 \mu \mathrm{g}$ and this declined to 


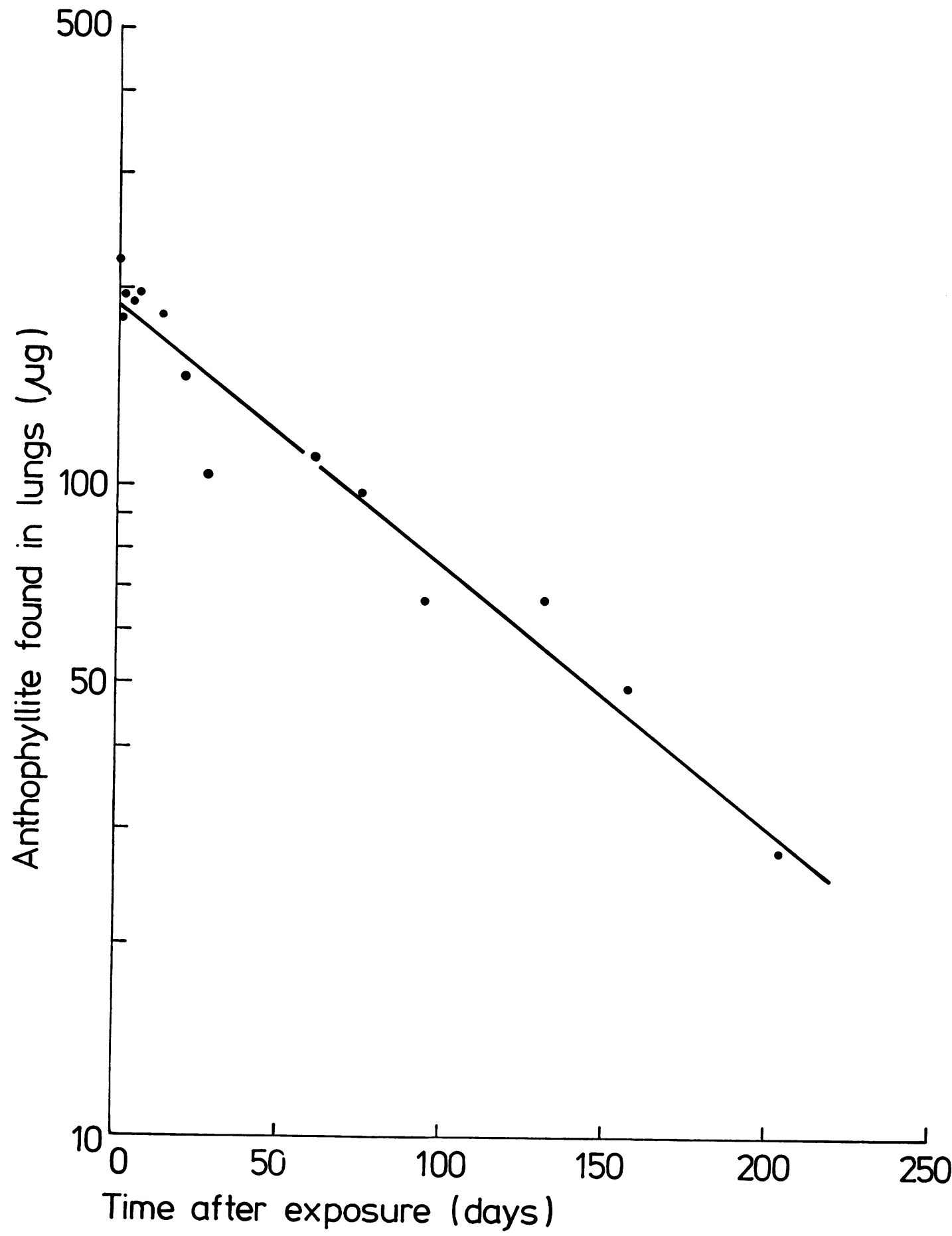

Fig. 1 Amount of anthophyllite found in the lungs of rats killed at various intervals after inhalation exposure. 
$30 \mu \mathrm{g}$ after 205 days. The line in Fig. 1 was computed by least squares and represents a single exponential expression with a half-time of 76 days.

ANTHOPHYLLITE IN FREE CELLS

The mean fibre content of alveolar macrophages recovered in combined physiological saline washes $5-8$ is shown in Fig. 2. It can be seen that, initially, each macrophage contained on average about $8 \mathrm{pg}$ of anthophyllite and after 90 days this had fallen to 2 pg. Because of the low levels of activity recovered in the various washings it was not possible accurately to determine cell loadings after 90 days.

LENGTH DISTRIBUTION OF AIRBORNE FIBRE The length distribution of anthophyllite fibres in the dust cloud sampled in the exposure chamber is given in the Table. Almost $80 \%$ of the airborne fibres were less than $5 \mu \mathrm{m}$ in length. Using a different type of aerosol dispenser, Timbrell (1970b) found that $71 \%$ of the airborne fibres generated from UICC anthophyllite were less than $5 \mu \mathrm{m}$ in length.

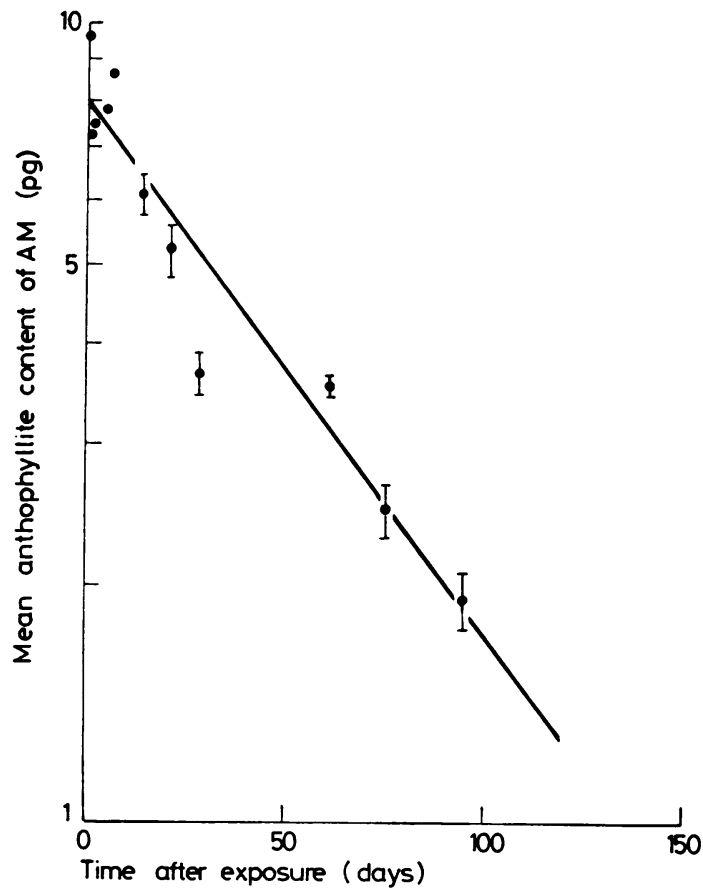

Fig. 2 Mean anthophyllite content of alveolar macrophages recovered by bronchopulmonary lavage with physiological saline from the lungs of rats killed at various intervals after inhalation exposure.
LENGTH DISTRIBUTION OF FIBRES

RECOVERED WITH BALANCED SALT

SOLUTION AND PHYSIOLOGICAL SALINE

For fibres recovered with balanced salt solution from the lungs of rats killed within seven days of exposure the proportion of long fibres was greater than that in the dust cloud (see Table). Presumably this is attributable to the interception of the longer fibres in the smaller airways of the lung and their recovery in the initial washes. After the first week, however, the proportion of fibres exceeding $20 \mu \mathrm{m}$ in length was generally less than $1 \%$. In the physiological saline washes the proportion of fibres less than $5 \mu \mathrm{m}$ in length showed a steady fall, with a corresponding increase in fibres up to $40 \mu \mathrm{m}$; the frequency of fibres exceeding $40 \mu \mathrm{m}$ in length was invariably less than $0.5 \%$.

\section{LENGTH DISTRIBUTION OF FIBRES} RECOVERED FROM THE LUNG

The length distributions of fibres recovered from the lungs of rats killed at various times are shown in the Table. The prevalence of fibres less than $5 \mu \mathrm{m}$ in length falls with time while that of fibres longer than $10 \mu \mathrm{m}$ increases. This increase appears to be most marked with the longer fibres.

\section{Discussion}

RETENTION OF ANTHOPHYLLITE IN THE LUNG AND IN FREE CELLS

The retention of anthophyllite in the lungs of these animals can be described in terms of a single exponential expression with a half-time of 76 days (Fig. 1). In earlier experiments of shorter duration Morgan et al. (1977a) obtained a value of 55 days with the same material. A half-time of 76 days corresponds to an average daily elimination from the lungs of $0.9 \%$ of the retained fibre. Once material deposited in the conducting airways has been eliminated from the body, clearance from the alveolar region can be estimated by radiometric determination of fibre in faeces. In the present experiment, faeces were collected from each animal for at least two days before it was killed and the average daily excretion of anthophyllite expressed as a fraction of that retained. After 14 days when all the fibre present in faeces could be considered to have originated from the alveolar region of the lung, about $1.4 \%$ of the lung anthophyllite content was excreted daily. After 120 days this had fallen to $0.5 \%$. This indicates that the elimination of fibre from the lung cannot accurately be described by a single exponential expression over periods of several months and explains discrepancies in the 
Table Length distributions of fibres in various samples

\begin{tabular}{|c|c|c|c|c|c|c|}
\hline \multirow[t]{2}{*}{ Sample } & \multirow{2}{*}{$\begin{array}{l}\text { Time after } \\
\text { exposure (days) }\end{array}$} & \multicolumn{2}{|c|}{ Length of fibres $(\mu \mathrm{m})$} & \multirow[b]{2}{*}{$10-19 \cdot 9$} & \multirow[b]{2}{*}{$20-40$} & \multirow[b]{2}{*}{$>4 C$} \\
\hline & & $<5$ & $5-9.9$ & & & \\
\hline Airborne & - & 79 & 15 & 4 & 2 & $<0.5$ \\
\hline BSS wash & $\begin{array}{r}0 \\
1 \\
2 \\
7 \\
21 \\
28 \\
75 \\
158 \\
205\end{array}$ & $\begin{array}{l}63 \\
68 \\
66 \\
77 \\
77 \\
78 \\
75 \\
74 \\
75\end{array}$ & $\begin{array}{l}23 \\
16 \\
21 \\
16 \\
20 \\
17 \\
17 \\
19 \\
18\end{array}$ & $\begin{array}{r}9 \\
10 \\
7 \\
6 \\
3 \\
5 \\
7 \\
6 \\
6\end{array}$ & $\begin{aligned} & 4 \\
& 4 \\
& 5 \\
& 1 \\
&<<.5 \\
&< 0.5 \\
& 1 \\
&< 0.5 \\
& 1\end{aligned}$ & $\begin{array}{r}<1 \\
2 \\
1 \\
<0.5 \\
<0.5 \\
<0.5 \\
<0.5 \\
<0.5 \\
<0.5\end{array}$ \\
\hline PS wash & $\begin{array}{r}0 \\
1 \\
2 \\
7 \\
21 \\
28 \\
75 \\
158 \\
205\end{array}$ & $\begin{array}{l}78 \\
75 \\
73 \\
73 \\
73 \\
75 \\
71 \\
67 \\
63\end{array}$ & $\begin{array}{l}17 \\
16 \\
20 \\
20 \\
21 \\
19 \\
19 \\
21 \\
25\end{array}$ & $\begin{array}{l}4 \\
7 \\
6 \\
5 \\
4 \\
4 \\
7 \\
8 \\
9\end{array}$ & $\begin{array}{l}1 \\
2 \\
1 \\
1 \\
2 \\
2 \\
3 \\
4 \\
3\end{array}$ & $\begin{array}{l}<0.5 \\
<0.5 \\
<0.5 \\
<0.5 \\
<0.5 \\
<0.5 \\
<0.5 \\
<0.5 \\
<0.5\end{array}$ \\
\hline Lavaged lung lobe & $\begin{array}{r}0 \\
1 \\
2 \\
7 \\
21 \\
28 \\
75 \\
158 \\
205\end{array}$ & $\begin{array}{l}69 \\
71 \\
69 \\
65 \\
65 \\
68 \\
60 \\
60 \\
56\end{array}$ & $\begin{array}{l}18 \\
17 \\
18 \\
24 \\
22 \\
19 \\
18 \\
21 \\
16\end{array}$ & $\begin{array}{r}7 \\
8 \\
9 \\
7 \\
9 \\
8 \\
13 \\
10 \\
13\end{array}$ & $\begin{array}{r}4 \\
3 \\
2 \\
3 \\
3 \\
3 \\
6 \\
5 \\
10\end{array}$ & $\begin{array}{l}2 \\
1 \\
2 \\
1 \\
1 \\
2 \\
4 \\
4 \\
5\end{array}$ \\
\hline
\end{tabular}

BSS $=$ balanced salt solution; PS = physiological saline

half-time of clearance observed in experiments of different duration.

The mean anthophyllite content of free cells recovered from the alveolar spaces is shown in Fig. 2. Initially, each free cell contained on average about $8 \mathrm{pg}$ of anthophyllite and there is no evidence of a significant delay in reaching this value. This is in agreement with published (Morgan et al., 1977b) and more recent unpublished work which has shown that the uptake of fibres of both chrysotile and amphibole asbestiform minerals by alveolar macrophages is effectively complete within a few hours of deposition. The average free cell loading decreased to about 2 pg after 90 days, corresponding to a halftime of 45 days. The main reason for this decline is the clearance of fibre-containing cells via the airways and their replacement with fibre-free cells. If cells entered the alveolar spaces at the same rate at which they were removed, so that the numbers remained constant, then one would expect the average dust loading of the free cells to fall with the same halftime as that of lung retention. For the equivalent period, however, the lung retention half-time is considerably longer (64 days). There are two possible explanations for this difference: an increase in the number of free cells in the lung with age will have the effect of producing a more rapid decline; alterna- tively, the transfer of fibre into the alveolar wall or the pulmonary lymphatics will have the same effect.

FIBRE LENGTH DISTRIBUTION

After the end of the first week, the length distribution of fibres recovered with balanced salt solution is relatively constant with more than $90 \%$ of the fibres present being less than $10 \mu \mathrm{m}$, and less than $1 \%$ being longer than $40 \mu \mathrm{m}$. For fibres recovered with physiological saline however, there appears to be a significant decline in the proportion of fibres less than $5 \mu \mathrm{m}$ in length with a corresponding rise in the prevalence of longer fibres. This indicates that, of the fibres associated with the free cell population of the lung, those shorter than $5 \mu \mathrm{m}$ are being removed more rapidly than the longer ones. It is easy to imagine that movement over the alveolar surface of alveolar macrophages containing short fibres will not be impeded significantly, so that there is a finite possibility of such fibres being cleared via the conducting airways. Once fibres exceed a certain critical length, then they are more likely to affect the mobility of these cells. The average diameter (when rounded up) of the rat alveolar macrophage is about $12 \mu \mathrm{m}$ (Morgan et al., 1977b). Leadbetter and Corn (1972), who studied the length distribution of glass fibres in the rat lung, also suggested that short fibres (less than 


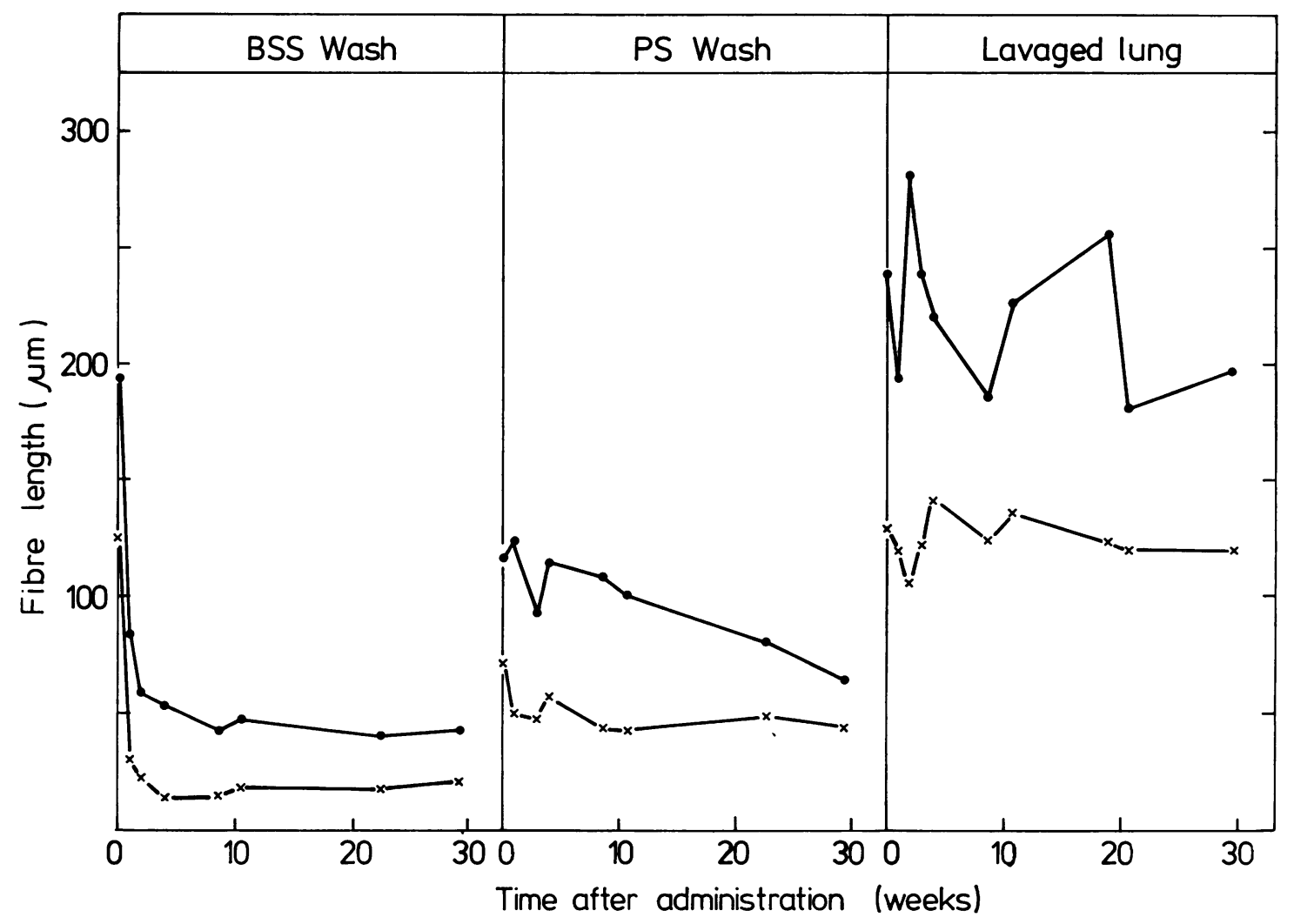

Fig. 3 Length of longest fibres observed in balanced salt solution (BSS) and physiological saline (PS) washes, and in the corresponding lavaged lung. longest fibre observed; $\times$ median length of longest fibres observed.

$4 \mu \mathrm{m}$ in length) were cleared more rapidly than longer ones.

The anthophyllite remaining in the lung after lavage consisted of (a) fibres in alveolar macrophages not removed by lavage and (b) fibres which cannot be recovered by lavage in the parenchyma and lymphatic systems of the lung. It is clear from the Table that the proportion of fibres less than $5 \mu \mathrm{m}$ long is consistently lower in the lung than in the corresponding physiological saline wash and that of fibres longer than $10 \mu \mathrm{m}$ is consistently greater. The proportions of all the longer size categories increased with time and this was most marked for fibres greater than $40 \mu \mathrm{m}$ in length. To obtain more information on dimensions of long fibres, lengths of at least 30 of the longest fibres visible on each filter were measured. Fig. 3 plots the length of the longest fibre observed, together with the median length of the 30 longest fibres. It can be seen that very long fibres (up to $200 \mu \mathrm{m}$ ) were recovered in the early balanced salt solution washes, but after a few weeks no fibre ex- ceeding $50 \mu \mathrm{m}$ in length was recovered, and very few exceeding $20 \mu \mathrm{m}$. This indicates that fibres longer than $50 \mu \mathrm{m}$ are not transported by the alveolar macrophages to the ciliated epithelium of the airways, although they are present in the lung. In the physiological saline washes the maximum length of fibre recovered appeared to decrease from a little over $100 \mu \mathrm{m}$ initially to $60-70 \mu \mathrm{m}$ after several months, while the median value remained relatively constant at $40-50 \mu \mathrm{m}$. In the lavaged lung, fibres of at least $180 \mu \mathrm{m}$ were observed in all samples and the median value was relatively constant at about 125 $\mu \mathrm{m}$. Fig. 4 shows fibres extracted (a) from the physiological saline wash and (b) from the lavaged lung of the rat killed 205 days after exposure, demonstrating the longer fibres which were recovered from the lung.

It is clear that fibres which exceed $100 \mu \mathrm{m}$ in length and which are present in the lung cannot be recovered by lavage. This could be attributable either to the dimensions of such fibres impeding their 

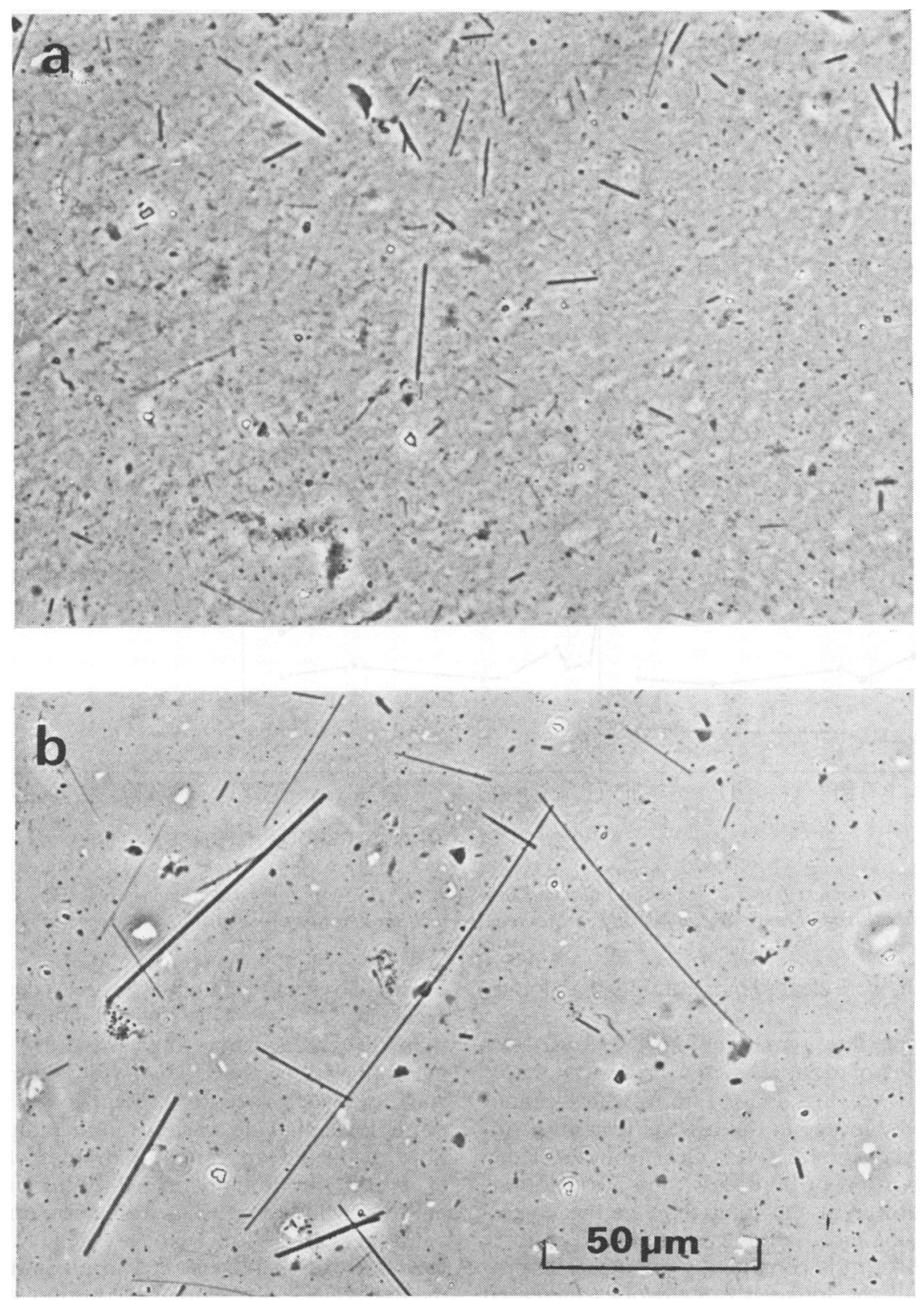

Fig. 4 Fibres from the lungs of a rat killed $205 d$ after exposure to anthophyllite asbestos. Fibres observed with a Zeiss Photomicroscope III ( $\times$ 550) under phase contrast. 4a Fibres recovered from lungs by physiological saline lavage. $4 \mathrm{~b}$ Fibres extracted from lavaged lung, showing longer fibres not recovered by lavage.

recovery in the lavage fluid, or to the possibility that such fibres are no longer free in the non-ciliated regions of the lung and are contained wholly or in part in the alveolar wall. Consideration of the dimensions of the rat alveolus (less than $150 \mu \mathrm{m}$ in 
such fibres into the alveolar wall with resulting damage to the epithelial cells. It is not possible to deduce from the present study whether very long fibres present in the lung remain intact or are eventually broken down. However, by measuring the absolute frequency of such fibres in lungs of rats killed serially over long periods it will be possible to determine their persistence.

The significance of fibre length in the aetiology of asbestos-induced lung diseases has been discussed by Timbrell (1973) who calculated that interception is likely to prevent fibres longer than $200 \mu \mathrm{m}$ penetrating the human nasal passages. The present study indicates that, although there is preferential deposition of longer fibres in the smaller conducting airways, anthophyllite fibres exceeding $200 \mu \mathrm{m}$ in length can penetrate to regions of the respiratory tract of the rat from which they cannot be removed by mucociliary action. There is increasing evidence to suggest that the fibrogenic activity of asbestos is associated with fibres exceeding a critical length. Wright and Kuschner (1977) have shown that fibres less than $10 \mu \mathrm{m}$ in length, administered to guinea pigs by intratracheal instillation, did not produce fibrosis either in lung tissue or in lymph nodes. Long fibres of the identical material, administered by the same route, produced extensive interstitial fibrosis. Hilscher (1972), who administered chrysotile and crocidolite to the rat by intraperitoneal injection, found that longer fibres produced fibrosis while the shorter (milled) fibres did not. The work of Stanton and Wrench (1972) and of other workers indicates that long fibres are also more effective than short for inducing mesothelial tumours in experimental animals. The fibrogenic response to longer fibres could arise either from the leakage of tissuedamaging enzymes from alveolar macrophages involved in the incomplete phagocytosis of long fibres, or from damage to the alveolar wall resulting from the penetration of long fibres. Clearly, more work is required regarding the fate of fibre deposited in the lung and, in particular, relating to the persistence of very long fibres and to their movement within the parenchyma.

The authors wish to acknowledge the support of the Institute of Occupational and Environmental Health (Montreal) and of the EEC Environmental Research Programme (Contract No 127-74-1 ENV UK).

\section{References}

Ashcroft, T., and Heppleston, A. G. (1973). Asbestos fibre concentration in relation to pulmonary reaction. In Proceedings of a Conference on Biological Effects of Asbestos, Lyon, 1972, pp. 236-237. Edited by P. Bogovski, J. C. Gilson, V. Timbrell and J. C. Wagner. International
Agency for Research on Cancer, Scientific Publication No. 8. IARC: Lyon.

Becklake, M. R. (1976). Asbestos-related diseases of the lung and other organs: their epidemiology and implications for clinical practice. American Review of Respiratory Diseases, 114, 187-227.

Brain, J. D., and Frank, R. (1973). Recovery of free cells from rat lungs by repeated washings. Journal of Applied Physio$\log y, 34,63-69$.

Clarke, W. J., and Bair, W. J. (1964). Plutonium inhalation studies VI. Pathologic effects of inhaled plutonium particles in dogs. Health Physics, 10, 391-398.

Hilscher, W. (1972). Experimental asbestosis in Wistar rats. Zentralblatt für Allgemeine Pathologie und Pathologisch Anatomie, 116, 413-416.

Leadbetter, M. R., and Corn, M. (1972). Particle size distribution of rat lung residues after exposure to fibreglass dust clouds. American Industrial Hygiene Association Journal, 33, 511-522.

Morgan, A., Evans, J. C., and Holmes, A. (1977a). Deposition and clearance of inhaled fibrous minerals in the rat. Studies using radioactive tracer techniques. In Inhaled Particles IV, Part 1, pp. 259-272. Edited by W. H. Walton. Pergamon Press, Oxford.

Morgan, A., Holmes, A., and Talbot, R. J. (1977b). The fate of asbestos fibres deposited in the rat lung. A quantitative approach. In Pulmonary Macrophage and Epithelial Cells. Proceedings of the 16th Annual Hanford Biology Symposium, pp. 436-450. Edited by C. L. Sanders, R. P. Schneider, G. E. Dagle and H. A. Ragan. CONF-760927. National Technical Information Service: Springfield, USA.

Sanders, C. L., and Cannon, W. C. (1975). Toxicology of high-fired beryllium oxide inhaled by rodents. Archives of Environmental Health, 30, 546-551.

Sanders, C. L., and Dagle, G. E. (1974). Studies of pulmonary carcinogenesis in rodents following inhalation of transuranic compounds. In Experimental Lung Cancer, Carcinogenesis and Bioassays, pp. 422-429. Edited by E. Karbe and J. F. Park. Springer-Verlag: Berlin.

Stanton, M. F., and Wrench, C. J. (1972). Mechanisms of mesothelioma induction with asbestos and fibrous glass. Journal of the National Cancer Institute, 48, 797-821.

Timbrell, V., Gilson, J. C., and Webster, I. (1968). UICC standard reference samples of asbestos. International Journal of Cancer, 3, 406-408.

Timbrell, V., Pooley, F., and Wagner, J. C. (1970a). Characteristics of respirable asbestos fibres. In Proceedings of an International Conference on Pneumoconiosis, Johannesburg, 1969, pp. 120-125. Edited by H. A. Shapiro. Oxford University Press: London.

Timbrell, V. (1970b). Characteristics of the International Union Against Cancer standard reference samples of asbestos. In Proceedings of an International Conference on Pneumoconiosis, Johannesburg, 1969, pp. 28-36. Edited by H. A. Shapiro. Oxford University Press: London.

Timbrell, V. (1973). Physical factors as etiological mechanisms. In Proceedings of a Conference on Biological Effects of Asbestos, Lyon, 1972, pp. 295-303. Edited by P. Bogovski, J. C. Gilson, V. Timbrell, and J. C. Wagner. International Agency for Research on Cancer, Scientific Publication No. 8. IARC: Lyon.

Voelz, G., Umbarger, J., McIlroy, J., and Healy, J. (1976). Considerations in the assessment of plutonium deposition in man. In Proceedings of a Seminar on Diagnosis and Treatment of Incorporated Radionuclides, Vienna, 1975. International Atomic Energy Authority: Vienna.

Wright, G. W., and Kuschner, M. (1977). The influence of varying lengths of glass and asbestos fibres on tissue response in guinea pigs. In Inhaled Particles IV, Part 2, pp. 455-474. Edited by W. H. Walton. Pergamon Press, Oxford. 